\title{
Recent progress in identification and characterization of loci associated with sex-linked congenital cataract
}

\author{
D.D. Zhang ${ }^{1 *}$, J.Z. Du ${ }^{1 *}$, J. Topolewski ${ }^{2}$ and X.M. Wang ${ }^{3}$
}

${ }^{1}$ Sichuan Key Laboratory for Disease Gene Study, Sichuan Academy of Medical Science and Sichuan Provincial People's Hospital, Sichuan, China

${ }^{2}$ Department of Infectious Diseases, University of Georgia, Athens, GA, USA ${ }^{3}$ Sichuan-Hong Kong Rehabilitation Center,

Sichuan Academy of Medical Science and Sichuan Provincial People's Hospital, Sichuan, China

*These authors contributed equally to this study.

Corresponding author: D.D. Zhang

E-mail: zhangdd25@126.com

Genet. Mol. Res. 15 (3): gmr. 15038600

Received March 3, 2016

Accepted April 25, 2016

Published July 29, 2016

DOI http://dx.doi.org/10.4238/gmr. 15038600

Copyright $(C 2016$ The Authors. This is an open-access article distributed under the terms of the Creative Commons Attribution ShareAlike (CC BY-SA) 4.0 License.

ABSTRACT. Congenital cataract is a common cause of blindness in children; however, its pathogenesis remains unclear. Genetic factors have been shown to play an important role in the pathogenesis of congenital cataract. The current genetic models of congenital cataract include autosomal dominant, autosomal recessive, and sex-linked inheritance. Sex-linked congenital cataract could be inherited through the $\mathrm{X}$ or $\mathrm{Y}$ chromosome. Congenital cataract is a symptom associated with several X-linked disorders, including Nance-Horan syndrome, 
Lowe syndrome, Conradi-Hünermann-Happle syndrome, oculo-faciocardio-dental syndrome, and Alport syndrome. On the other hand, the mechanism and characteristics of Y-linked congenital cataract remains to be identified. Despite its rarity, sex-linked congenital cataract has been known to seriously affect the quality of life of patients. In this review, we present our current understanding of the genes and loci associated with sex-linked congenital cataract. This could help identify novel approaches for the prevention, early diagnosis, and comprehensive disease treatment.

Key words: Congenital cataract; Sex-linked inheritance; Genes; Loci; Sequencing

\section{INTRODUCTION}

Congenital cataract is a serious disorder affecting lens development, and the second largest cause of blindness in children (Reddy et al., 2004). Clinical symptoms of cataract include the manifestations of visual loss and amblyopia, and may appear in children at birth or during early childhood. One to six of 10,000 newborns in developed countries and 5-15/10,000 newborns in developing countries are afflicted with congenital cataract (Kumar et al., 2013). Genetic factors are known to play prominent roles in the pathogenesis of congenital cataract. Moreover, congenital cataract has significant genetic heterogeneity, with the genetic models ranging from autosomal dominant (Kong et al., 2015) and autosomal recessive to and sexlinkage inheritance. However, the pathogenesis of this disorder remains to be elucidated.

Despite the large number of reviews on congenital cataract, none have focused on sexlinked congenital cataract. In this review, we have provided a brief overview of the advances in sex-linked congenital cataract research.

Sex-linked congenital cataract could be inherited through the X- or Y-chromosome. $\mathrm{X}$-linked congenital cataract is characterized by syndromic congenital cataract along with a combination of other systemic abnormalities, such as mono-ocular or bi-ocular lens opacity, mental retardation, urinary system abnormalities, or hearing impairment (Mihelec et al., 2008). This abnormality is relatively rare, but has a serious impact on the quality of life of affected patients. Congenital cataract is a symptom observed in several X-linked disorders such as Nance-Horan syndrome, Lowe syndrome, oculo-facio-cardio-dental syndrome, Alport syndrome, and Conradi-Hünermann-Happle syndrome (Shiels et al., 2010), among others. The chromosome localization and genes involved in congenital cataract in these syndromes are summarized in Table 1. On the other hand, Y-linked congenital cataract primarily affects people with a French pedigree (Feingold et al., 1979).

Table 1. X-linked genes and loci responsible for syndromic congenital cataract.

\begin{tabular}{l|l|c}
\hline Syndrome & Gene & Chromosome \\
\hline Nance-Horan syndrome & NHS & Xp21.1-p22.3 \\
\hline Lowe syndrome & OCRL1 & Xq26.1 \\
\hline Conradi-Hünermann-Happle & EBP & Xp11.22-p11.23 \\
\hline Oculo-facio-cardio-dental & BCOR & Xp11.4 \\
\hline Alport syndrome & COL4A5 & Xq21-q22 \\
\hline
\end{tabular}

$N H S$, NHS actin remodeling regulator; OCRL1, oculocerebrorenal syndrome of Lowe 1; EBP, emopamil-binding protein; BCOR, BCL6 corepressor; COL4A5, collagen type IV alpha 5.

Genetics and Molecular Research 15 (3): gmr.15038600 


\section{STRATEGIES FOR GENE IDENTIFICATION}

The methods used currently in genetic research include linkage analysis, exon sequencing, and whole exon sequencing (WES), which are subsequently described.

\section{Linkage analysis}

Linkage analysis is a method based on familial studies, and is mainly used for the analysis of single gene genetic diseases. This method helps in screening for candidate gene loci of sex-linked congenital cataract. However, it has certain limitations: the efficiency of small family analyses is very low, if it is carried out based on the LOD value. The loci in the Xp22.31-p22.13 region associated with Nance-Horan syndrome was refined by linkage analysis (Toutain et al., 1997).

\section{Exome sequencing}

Exome sequencing is used to analyze the existence of base variations and genotyping via the DNA capture of the exome region. This technique is of great value in the study of the mutation sites in known disease genes. This method is simple, fast, of high resolution, and produces relatively long sequence fragments. Tug et al. (2013) reported a new frameshift mutation c.558insA (p.E186Efs11X) in exon 1 of NHS in related Turkish Nance-Horan patients by screening for, and sequencing, NHS using this method.

\section{WES}

WES is a genomic analysis method used in high throughput sequencing. This method is based on exome sequencing, with an added advantage of positional cloning. It is often used in the identification of causative genes and mutations of various diseases, including melanoma, urinary tract tumor, Parkinson's disease, primary microcephaly, diabetes, and congenital anomalies in the kidneys and urinary tract (Huang et al., 2014; Kosfeld et al., 2015). Furthermore, WES is also used to determine the pathogenesis of intellectual disabilities, original dwarf disease, as well as the formation of idiopathic pulmonary arterial hypertension (Retterer et al., 2015). It is also of great value in locating the causative gene of, and rare mutations in, diseases afflicting small families and sporadic cases, because of its high efficiency. Hong et al. (2014) compared 3 male patients with, and 2 female carriers of, NanceHoran syndrome in four generations of a Chinese family and in 2 normal male controls, using WES in combination with Sanger sequencing, and successfully identified a new mutation c.322G $>\mathrm{T}(\mathrm{E} 108 \mathrm{X})$ in exon 1 of $N H S$ correlated with Nance-Horan syndrome in these patients.

\section{X-LINKED GENES AND LOCI CAUSING SYNDROMIC CONGENITAL CATARACT}

\section{Nance-Horan syndrome}

Nance-Horan syndrome, first reported by Nance et al. (1974) and Horan and Billson (1974), is an X-linked recessive disorder characterized by syndromic congenital cataract and 
dysplasia in several systems, including the dental and craniofacial systems. The syndrome is also known as cataract-ear-tooth syndrome. Male patients with this disease present serious congenital cataracts in both eyes, resulting in visual loss, accompanied by congenital small cornea, small eyeballs, eyeball tremor, long and narrow facial appearance, protruding ears, and serrated teeth. Additionally, $30 \%$ of all patients display mental retardation. In comparison, females present a lens change to medium distant and show a point- or coral-like opacity about the $\mathrm{Y}$ crack, although their vision may not be affected (Florijn et al., 2006).

Evidence suggests that mutations in the NHS gene, located at Xp21.1-p22.3, could be associated with the Nance-Horan syndrome (Tug et al., 2013). This gene, comprising 10 exons, encodes at least 4 isoforms (subtypes) of the NHS protein: NHS- $A$ consists of 8 exons that encodes a 1630 -aa protein, and a large 350-kb intron; $N H S-B$, transcribed by exon $1 \mathrm{~b}$ and translated by exon 4, encodes a 1335 -aa protein; $N H S-C$, transcribed and translated by exon 1a, encodes a 1453-aa protein, and $N H S-1 A$, transcribed by NHS- $\alpha$-like exon 1, encodes a 1651-aa protein. NHS-A and NHS-1A are the two major subtypes that play a regulatory role in actin remodeling. NHS maintains the cytoskeleton by maintaining the integrity of the actin ring and controlling the actin formation (Tug et al., 2013).

The studies conducted on Nance-Horan syndrome have so far reported 33 mutations in NHS. Recently, Khan et al. (2012) identified a novel mutation p.Lys744AsnfsX15 in NHS in 7 patients with the Nance-Horan comprehensive syndrome pedigree, presenting congenital cataract. This mutation was identified in four female patients with Y center lens opacity, and in 2 female and 3 male asymptomatic patients, implying that this is not a causative mutation of Nance-Horan syndrome. Hong et al. (2014) reported a new mutation c.322G $>$ T (E108X) in exon 1 of $N H S$, located in a highly-conserved region in the NHS protein. This mutation results in the conversion of a codon for glutamate to a termination codon, changes in the cellular location of NHS, degradation of NHS mRNA, and truncations in the NHS protein. This suggested that this mutation could be related to the pathogenesis of Nance-Horan syndrome. $\mathrm{Li}$ et al. (2015) identified a new 1-bp deletion in exon 4 of NHS [c.852delG(p.S285PfsX13)], by using an exon capture technology and high-throughput sequencing. Previous studies have expanded the NHS mutation spectrum, providing a foundation for the clinical diagnosis of Nance-Horan syndrome.

\section{Lowe syndrome}

Lowe syndrome, or the eye-brain-kidney syndrome, is a rare X-linked recessive syndrome affecting multiple systems, with a morbidity rate of $1 / 200,000-1 / 500,000$ at birth (Recker et al., 2015). This syndrome is clinically characterized by dysplasia of the eye, congenital cataracts, and infantile glaucoma, leading to visual loss. Additionally, children afflicted with this syndrome present neurological handicaps, including hypotonia and hypophrenia. Additional characteristics include defects in the renal tubular function, vitamin D deficiency (rickets), and scoliosis. Congenital cataract can also be developed during the early stages of pregnancy, in association with the Lowe syndrome (Loi, 2006).

Mutations in OCRL1, a member of the inositol-5-phosphatase family located at chromosome Xq26.1 and consisting of 24 exons, is believed to be associated with the development of Lowe syndrome (Attree et al., 1992). Exon 1 is the noncoding region of this gene, while exon 2-23 are coding regions that regulate protein polymerization, cell migration, and cell-cell interactions. This gene also plays an important role in the development of

Genetics and Molecular Research 15 (3): gmr.15038600 
renal tubules, lens, and the brain. Although $O C R L 1$ is widely expressed in different tissues, its expression may be defective during the development of the eye, kidney, and central neurological tissues, among others (Pirruccello and DeCamilli, 2012).

So far, over 200 mutations have been identified in ORCL1, 90\% of which are located at 2 hot point regions in exon 1-18 and 19-23. Kanik et al. (2013) reported 2 nucleotide deletions that resulted in a novel frameshift change (p.Val787GlyfsX788) in exon 22 of ORCL1 in a Turkish family with Lowe syndrome. Meanwhile, Zhang et al. (2013) identified two mutations, g.1897delT in exon 18 and g.1470delG in exon 15, in two unrelated Chinese patients with Lowe syndrome. Sugimoto et al. (2014) described a new mutation, 2039T $>$ C (Ser680Phe), in exon 18 of OCRL1, while Liu et al. (2015) identified a new insertion c.2367insA (P. Ala813X) in exon 22 of OCRL1 in Chinese children with Lowe syndrome by sequencing and bioinformatic analysis.

\section{Oculo-facio-cardio-dental syndrome}

Oculo-facio-cardio-dental syndrome, named by Gorlin et al. (1996) and first reported by Hayward (1980), is an X-linked dominant inheritance syndrome involving multiple systems that is often fatal in males. This disorder is characterized by congenital cataract, congenital small eyes, secondary glaucoma, facial deformities, mental retardation, attention deficit hyperactivity, hearing impairment, and congenital heart disease ( $\mathrm{Ng}$ et al., 2004).

Mutations in $B C O R$, located at Xp11.4, are shown to be associated with the oculofacio-cardio-dental syndrome. $B C O R$, which comprises 14 exons, encodes the $\mathrm{CO}$ repressor protein in $\mathrm{BLC6}$, and formats the $\mathrm{POZ} /$ zinc pointing transcription repressor in the germinal center. The protein selectively interacts with the POZ domain of BCL6. BCOR is expressed in many tissues, including the eyes, teeth, and the nerve canal, and plays an important role in the regulation of early embryo development (Lozic et al., 2012).

A majority of the $B C O R$ mutations associated with the oculo-facio-cardio-dental syndrome are frameshift and splice mutations, while a small number are deletion mutations (Ng et al., 2004). Lozic et al. (2012) reported a new heterozygous mutation, c.4438C $>\mathrm{T}$ (p.R1480*), in exon 11 of BCOR in identical twins with oculo-facio-cardio-dental syndrome by short tandem repeat analysis and sequencing. Danda et al. (2014) identified a novel mutation in exon 7 of $B C O R$, c.3490C $>$ T (p.R1164*), in two Indian sisters with oculo-faciocardio-dental syndrome, via sequencing. On the other hand, Di Stefano et al. (2015) identified an original loss of heterozygosity at a region $2.3-\mathrm{Mb}$ away from Xp11.4, including BCOR and $O T C$, in patients with oculo-facio-cardio-dental patients, via high resolution array comparison (A-CGH). Zhu et al. (2015) identified a novel missense mutation, c.G1619A, in BCOR in a 7-month boy with oculo-facio-cardio-dental syndrome. p.R540Q was identified to be associated with the phenotype of oculo-facio-cardio-dental syndrome, indicating that $B C O R$ might play a major role in the development of oculo-facio-cardio-dental syndrome.

\section{Conradi-Hünermann-Happle syndrome}

Conradi-Hünermann-Happle syndrome is an X-linked dominant chondrodysplasia punctate syndrome responsible for abnormalities in the skin, skeleton, and eyes. The main clinical characteristics of this syndrome include ichthyosis follicularis, skin atrophy, cicatricial alopecia, short stature, asymmetric limb shorting, craniofacial defects, and congenital cataract, among others. Braverman et al. (1999) suggested a correlation between the EBP gene and

Genetics and Molecular Research 15 (3): gmr.15038600 
morbidity in patients with Conradi-Hünermann-Happle syndrome.

The 7-kb EBP gene, located at chromosome Xp11.22-p11.23, is composed of 5 exons that encode the $27-\mathrm{kDa}$ EBP protein, comprising 230 amino acids. This endoplasmic reticulum protein contains 4 transmembrane domains that participate in cholesterol biosynthesis. Morice-Picard et al. (2011) reported a new heterozygous missense mutation c.199CT in a French child with Conradi-Hünermann-Happle syndrome, via sequencing and bioinformatic analysis. Arnold et al. (2012) identified a position mutation c.33C $>\mathrm{A}$ in the $E B P$ gene in a 7-year-old boy suffering from Conradi-Hünermann-Happle syndrome by sequencing analysis. This mutation (p.Y11X.) was also reported in a female patient displaying the above-mentioned symptoms. Lambrecht et al. (2014), who analyzed the EBP gene in a female patient with Conradi-Hünermann-Happle syndrome, identified a new heterozygous missense mutation c. $204 \mathrm{G}>\mathrm{T}$ (p.W68C) at exon 2 of the gene. Ozyurt et al. (2015) further reported an association between mutations in EBP and Conradi-Hünermann-Happle syndrome.

\section{Alport syndrome}

Alport syndrome, or hereditary nephritis, familial nephritis, or hereditary progressive glomerulonephritis, is a syndrome with a morbidity rate of 1:5000, and is chiefly characterized by progressive failure of renal function, sensorineural hearing loss, and congenital cataract. $\mathrm{X}$-linked dominant inheritance is the most common hereditary model responsible for the development of Alport syndrome. Patients with X-linked dominant inherited Alport syndrome present the COL4A5 mutation, while those with autosomal inherited Alport syndrome present mutations in COL4A3 or COL4A4 (Mochizuki et al., 1994).

COL4A5, located at Xq21-q22, encodes the $\alpha 5$ chain of type IV collagen. Baikara et al. (2015) identified a novel mutation G641E in exon 25 of COL4A5 in two Kazakh patients with Alport syndrome, which was not observed in normal subjects from this family, or in 200 normal control subjects, indicating its significance in Alport syndrome.

Additionally, congenital cataract is a symptom of Norrie syndrome, an X-linked recessive syndrome, located at the proximal end of Xpll.3 (Fangting et al., 2015). Syndromic congenital cataract is associated with over 15 X-linked disorders (Shiels et al., 2010). Several studies are currently in the process of identifying genes and loci related to X-linked congenital cataract.

\section{Y-LINKED CONGENITAL CATARACT}

A large number of X-linked disorders have been shown to present congenital cataract; however, so far, there has been only one report of Y-linked congenital cataract. Therefore, the existence of Y-linked congenital cataract remains to be conclusively verified (Feingold et al., 1979).

\section{CONCLUSIONS}

The clinical manifestations of congenital cataract inherited via the sex chromosomes are complex and varied, and include abnormal lens function, as well as multiple system abnormalities. Congenital cataract seriously compromises the quality of life of the patient, and is a heavy burden to the family of the patient and the society. The genotype-phenotype relationship of genes associated with X- or Y-linked congenital cataract remains unclear. A large number of reports focused on sex-linked congenital cataract are case reports because of

Genetics and Molecular Research 15 (3): gmr.15038600 
the difficulty in accurate identification of the causative gene. Moreover, the exact pathogenesis of this disease remains to be elucidated.

The study of causative genes of sex-linked congenital cataract is of great scientific value and practical significance, as it could help develop techniques for early diagnosis and effective therapy. The development of molecular genetics and technology has facilitated extensive investigations into the familial pedigree of congenital cataract via the use of new sequencing technologies such as whole genome sequencing and WES (Narumi et al., 2014). Consequently, this allows us to elucidate the pathogenesis of sex-linked congenital cataract at a molecular level and study the gene-gene and gene-environment interactions, which in turn could help provide comprehensive patient services. Additionally, this forms a basis for the development of novel prenatal diagnostic, genetic counseling, and therapeutic strategies, which would ultimately benefit the patients.

\section{Conflicts of interest}

The authors declare no conflict of interest.

\section{ACKNOWLEDGMENTS}

Research supported by grants provided by the National Natural Science Foundation of China (\#81271049 to D.D. Zhang), the Department of Science and Technology of Sichuan Province (\#SZ0022 to D.D. Zhang), and the Scientific Research Project of the Sichuan Provincial Health Department (\#150228 to D.D. Zhang).

\section{REFERENCES}

Arnold AW, Bruckner-Tuderman L, Has C, Happle R, et al. (2012). Conradi-Hunermann-Happle syndrome in males vs. MEND syndrome (male EBP disorder with neurological defects). Br. J. Dermatol. 166: 1309-1313. http://dx.doi. org/10.1111/j.1365-2133.2012.10808.x

Attree O, Olivos IM, Okabe I, Bailey LC, et al. (1992). The Lowe's oculocerebrorenal syndrome gene encodes a protein highly homologous to inositol polyphosphate-5-phosphatase. Nature 358: 239-242. http://dx.doi. org $/ 10.1038 / 358239 \mathrm{a} 0$

Baikara BT, Zholdybayeva EV, Rakhimova SE, Nigmatullina NB, et al. (2015). A novel mutation in a Kazakh family with X-linked Alport syndrome. PLoS One 10: e0132010. http://dx.doi.org/10.1371/journal.pone.0132010

Braverman N, Lin P, Moebius FF, Obie C, et al. (1999). Mutations in the gene encoding 3 beta-hydroxysteroid-delta 8 , delta 7-isomerase cause X-linked dominant Conradi-Hunermann syndrome. Nat. Genet. 22: 291-294. http://dx.doi. org $/ 10.1038 / 10357$

Danda S, van Rahden VA, John D, Paul P, et al. (2014). Evidence of germline mosaicism for a novel BCOR mutation in two Indian sisters with oculo-facio-cardio-dental syndrome. Mol. Syndromo. 15: 251-256. http://dx.doi. org $/ 10.1159 / 000365768$

Di Stefano C, Lombardo B, Fabbricatore C, Munno C, et al. (2015). Oculo-facio-cardio-dental (OFCD) syndrome: the first Italian case of BCOR and co-occurring OTC gene deletion. Gene 559: 203-206. http://dx.doi.org/10.1016/j. gene.2015.01.044

Fangting L, Lvzhen H and Xiaoxin L (2015). A novel c.2T>A NDP missense mutation in a Chinese family with Norrie disease. Acta Ophthalmol. 11: 7 .

Feingold J, Raoul O, See G, Delthil S, et al. (1979). Congenital cataract linked to the Y chromosome. J. Genet. Hum. 27: 67-69.

Florijn RJ, Loves W, Maillette de Buy Wenniger-Prick LJ, Mannens MM, et al. (2006). New mutations in the NHS gene in Nance-Horan Syndrome families from the Netherlands. Eur. J. Hum. Genet. 14: 986-990. http://dx.doi.org/10.1038/ sj.ejhg. 5201671

Genetics and Molecular Research 15 (3): gmr.15038600 
Gorlin RJ, Marashi AH and Obwegeser HL (1996). Oculo-facio-cardio- dental (OFCD) syndrome. Am. J. Med. Genet. 63: 290-292.http://dx.doi.org/10.1002/(SICI)1096-8628(19960503)63:1<290::AID-AJMG47>3.0.CO;2-G

Hayward JR (1980). Cuspid gigantism. Oral Surg. Oral Med. Oral Pathol. 149: 500-501.http://dx.doi.org/10.1016/0030$\underline{4220(80) 90070-5}$

Hong N, Chen YH, Xie C, Xu BS, et al. (2014). Identification of a novel mutation in a Chinese family with NanceHoran syndrome by whole exome sequencing. J. Zhejiang Univ. Sci. B. 15: 727-734. http://dx.doi.org/10.1631/jzus. B1300321

Horan MB and Billson FA (1974). X-linked cataract and Hutchinsonian teeth. Aust. Paediatr. J. 10: 98-102.

Huang Y, Zheng J, Hu JD, Wu YA, et al. (2014). Discovery of somatic mutations in the progression of chronic myeloid leukemia by whole-exome sequencing. Genet. Mol. Res. 13: 945-953.http://dx.doi.org/10.4238/2014.February.19.5

Kanik A, Kasap-Demir B, Atesli R, Eliacik K, et al. (2013). A novel OCRL1 gene mutation in a Turkish child with Lowe syndrome. Turk. J. Pediatr. 55: 82-85.

Khan AO, Aldahmesh MA, Mohamed JY and Alkuraya FS (2012). Phenotype-genotype correlation in potential female carriers of X-linked developmental cataract (Nance-Horan syndrome). Ophthalmic Genet. 33: 89-95. http://dx.doi.or $\mathrm{g} / 10.3109 / 13816810.2011 .634881$

Kong XD, Liu N, Shi HR, Dong JM, et al. (2015). A novel 3-base pair deletion of the CRYAA gene identified in a large Chinese pedigree featuring autosomal dominant congenital perinuclear cataract. Genet. Mol. Res. 14: 426-432. http:// dx.doi.org/10.4238/2015.January.23.16

Kosfeld A, Kreuzer M, Daniel C, Brand F, et al. (2015). Whole-exome sequencing identifies mutations of TBC1D1 encoding a Rab-GTPase-activating protein in patients with congenital anomalies of the kidneys and urinary tract (CAKUT). Hum. Genet. 11: 16.

Kumar M, Agarwal T, Kaur P, Kumar M, et al. (2013). Molecular and structural analysis of genetic variations in congenital cataract. Mol. Vis. 19: 2436-2450.

Lambrecht C, Wouters C, Van Esch H, Moens P, et al. (2014). Conradi-Hunermann-Happle syndrome: a novel heterozygous missense mutation, c.204G>T (p.W68C). Pediatr. Dermatol. 31: 493-496.http://dx.doi.org/10.1111/pde.12336

Li A, Li B, Wu L, Yang L, et al. (2015). Identification of a novel NHS mutation in a Chinese family with Nance-Horan syndrome. Curr. Eye Res. 40: 434-438.http://dx.doi.org/10.3109/02713683.2014.959606

Liu T, Yue Z, Wang H, Tong H, et al. (2015). Novel mutation of OCRL1 in Lowe syndrome. Indian J. Pediatr. 82: 89-92. http://dx.doi.org/10.1007/s12098-014-1581-6

Loi M (2006). Lowe syndrome. Orphanet. J. Rare Dis. 1: 16. http://dx.doi.org/10.1186/1750-1172-1-16

Lozic B, Jubković J, Pandurić DG, Saltvig I, et al. (2012). Oculo-facio-cardio-dental syndrome in three succeeding generations: genotypic data and phenotypic features. Braz. J. Med. Biol. Res. 45: 1315-1319.

Mihelec M, St Heaps L, Flaherty M, Billson F, et al. (2008). Chromosomal rearrangements and novel genes in disorders of eye development, cataract and glaucoma. Twin Res. Hum. Genet. 11: 412-421. http://dx.doi.org/10.1375/ $\underline{\text { twin.11.4.412 }}$

Mochizuki T, Lemmink HH, Mariyama M, Antignac C, et al. (1994). Identification of mutations in the alpha 3(IV) and alpha 4(IV) collagen genes in autosomal recessive Alport syndrome. Nat. Genet. 8: 77-81.http://dx.doi.org/10.1038/ ng0994-77

Morice-Picard F, Kostrzewa E, Wolf C, Benlian P, et al. (2011). Evidence of postzygotic mosaicism in a transmitted form of Conradi-Hunermann-Happle syndrome associated with a novel EBP mutation. Arch. Dermatol. 147: 1073-1076. http://dx.doi.org/10.1001/archdermatol.2011.230

Nance WE, Warburg M, Bixle D and Helveston EM (1974). Congenital X-linked cataract, dental anomalies and brachymetacarpalia. Birth Defects Orig. Artic. Ser. 10: 285-291.

Narumi Y, Nishina S, Tokimitsu M, Aoki Y, et al. (2014). Identification of a novel missense mutation of MAF in a Japanese family with congenital cataract by whole exome sequencing: a clinical report and review of literature. $A m$. J. Med. Genet. A 164: 1272-1276. http://dx.doi.org/10.1002/ajmg.a.36433

Ng D, Thakker N, Corcoran CM, Donnai D, et al. (2004). Oculofaciocardiodental and Lenz microphthalmia syndromes result from distinct classes of mutations in BCOR. Nat. Genet. 36: 411-416. http://dx.doi.org/10.1038/ng1321

Ozyurt K, Subasioglu A, Ozturk P, Inci R, et al. (2015). Emopamil binding protein mutation in Conradi-HunermannHapple syndrome representing plaque-type psoriasis. Indian J. Dermatol. 60: 216.

Pirruccello M and DeCamilli P (2012). Inositol 5-phosphatases: insights from the Lowe syndrome protein OCRL 26. Trends Biochem. Sci. 37: 134-143. http://dx.doi.org/10.1016/j.tibs.2012.01.002

Recker F, Zaniew M, Böckenhauer D, Miglietti N, et al. (2015). Characterization of 28 novel patients expands the mutational and phenotypic spectrum of Lowe syndrome. Pediatr. Nephrol. 30: 931-943. http://dx.doi.org/10.1007/ $\underline{\mathrm{s} 00467-014-3013-2}$

Genetics and Molecular Research 15 (3): gmr.15038600 
Reddy MA, Francis PJ, Berry V, Bhattacharya SS, et al. (2004). Molecular genetic basis of inherited cataract and associated phenotypes. Surv. Ophthalmol. 49: 300-315. http://dx.doi.org/10.1016/j.survophthal.2004.02.013

Retterer K, Juusola J, Cho MT, Vitazka P, et al. (2015). Clinical application of whole-exome sequencing across clinical indications. Genet. Med. 12: 3.

Shiels A, Bennett TM and Hejtmancik JF (2010). Cat-Map: putting cataract on the map. Mol. Vis. 16: 2007-2015.

Sugimoto K, Nishi H, Miyazawa T, Fujita S, et al. (2014). A novel OCRL1 mutation in a patient with the mild phenotype of Lowe syndrome. Tohoku J. Exp. Med. 232: 163-166. http://dx.doi.org/10.1620/tjem.232.163

Toutain A, Ronce N, Dessay B, Robb L, et al. (1997). Nance-Horan syndrome: linkage analysis in 4 families refines localization in Xp22.31-p22.13 region. Hum. Genet. 99: 256-261. http://dx.doi.org/10.1007/s004390050349

Tug E, Dilek NF, Javadiyan S, Burdon KP, et al. (2013). A Turkish family with Nance-Horan Syndrome due to a novel mutation. Gene 525: 141-145.http://dx.doi.org/10.1016/j.gene.2013.03.094

Zhang YQ, Wang F, Ding J, Yan H, et al. (2013). Novel OCRL mutations in Chinese children with Lowe syndrome. World J. Pediatr. 9: 53-57.http://dx.doi.org/10.1007/s12519-013-0406-4

Zhu X, Dai FR, Wang J, Zhang Y, et al. (2015). Novel BCOR mutation in a boy with Lenz microphthalmia/oculo-faciocardio-dental (OFCD) syndrome. Gene 571: 142-144. http://dx.doi.org/10.1016/j.gene.2015.07.061

Genetics and Molecular Research 15 (3): gmr.15038600 